\title{
Nepalese populations show no association between the distribution of malaria and protective alleles
}

Cátia P Caetano ${ }^{1}$, Thirsa Kraaijenbrink ${ }^{2}$, Nirmal M Tuladhar ${ }^{3}$, George L van Driem ${ }^{4}$, Peter de Knijff $^{2}$, Chris Tyler-Smith ${ }^{1}$, Denise R Carvalho-Silva ${ }^{1 *}$

${ }^{1}$ The Wellcome Trust Sanger Institute, Wellcome Trust Genome Campus, Hinxton, United Kingdom; ${ }^{2}$ Department of Human Genetics, Leiden University Medical Centre, The Netherlands; ${ }^{3}$ Centre for Nepal and Asian Studies of Tribhuvan University, Kirtipur, Nepal; ${ }^{4}$ Himalayan Languages Project, Leiden University, The Netherlands

${ }^{*}$ Correspondence to: Denise Carvalho-Silva, The Wellcome Trust Sanger Institute, Wellcome Trust Genome Campus, Hinxton, CB10 1SA, UK. E-mail: ds8@sanger.ac.uk, Tel: +44 (0)1223 834244,Fax: +44 (0)1223 494919

Journal of Molecular and Genetic Medicine (2006), 2(1), 101-106

(C) Copyright Cátia P Caetano et al

(Received 07 October 2006; Revised 06 November 2006; Accepted 08 November 2006; Published online 23 November 2006)

\begin{abstract}
Malaria is perhaps the most important parasitic infection and strongest known force for selection in the recent evolutionary history of the human genome. Genetically-determined resistance to malaria has been welldocumented in some populations, mainly from Africa. The disease is also endemic in South Asia, the world's second most populous region, where resistance to malaria has also been observed, for example in Nepal. The biological basis of this resistance, however, remains unclear. We have therefore investigated whether known African resistance alleles also confer resistance in Asia. We typed seven single nucleotide polymorphisms (SNPs) from the genes $H B B, F Y, G 6 P D, T N F S F 5, T N F, N O S 2$ and FCGR2A in 928 healthy individuals from Nepal. Five loci were found to be fixed for the non-resistant allele (HBB, FY, G6PD, TNFSF5 and NOS2). The remaining two $(r s 1800629$ and $r s 1801274)$ showed the presence of the resistant allele at a frequency of 93\% and $27 \%$ in TNF and FCGR2A, respectively. However, the frequencies of these alleles did not differ significantly between highland (susceptible) and lowland (resistant) populations. The observed differences in allele and genotype frequencies in Nepalese populations therefore seem to reflect demographic processes or other selective forces in the Himalayan region, rather than malaria selection pressure acting on these alleles.
\end{abstract}

KEYWORDS: Malaria, Himalayas, Nepal, single nucleotide polymorphisms, selection, resistance

\section{INTRODUCTION}

Malaria, the parasitic disease of the red blood cell caused by Plasmodium $s p$, kills more than one million children each year in Africa alone (Kwiatkowski, 2005). The strong selective pressure that malaria exerts has been shaping the human genome for at least 6,000 years (Rich et al, 1998) and the disease is the driving force behind several genetic disorders, such as the sickle cell trait, glucose-6-phosphate dehydrogenase deficiency and thalassemia (Kwiatkowski, 2005). The single nucleotide polymorphisms (SNPs) responsible for the above traits afford protection against malarial parasites and hence have been maintained in some human populations by a mechanism of balancing selection
(Boldt et al, 2006). In addition to the erythrocyte variants, SNPs in genes that modulate the immune response have been also reported to confer resistance to malaria (Kwiatkowski, 2005).

Different human populations may have developed independent and different responses to malaria, but the bulk of studies on the genetics of those responses has been performed in Africa, where remarkable examples of differences in protection can be found (Kwiatkowski, 2005). Most of the sub-Saharan African populations, for instance, are completely resistant to the malaria caused by $P$. vivax, whereas populations outside Africa are not. The protection in Africans is believed to be associated with a SNP in the 
promoter region of the $F Y$ gene (Tournamille et al, 1995), which abolishes transcription in erythrocytes and consequently prevents the parasite from invading the red blood cells (Miller et al, 1976).

Malaria is also endemic in South Asian countries such as India, Nepal, Bhutan, and Sri Lanka, (Kondrashin, 1992). In Nepal, for example, the WHO reported 4,637 cases in 2004, from a population of 27.3 million; $7.9 \%$ of the cases were caused by $P$. falciparum (http://w3.whosea.org/en/Section10/Section21/Section340.htm). However, the probable number of cases was judged to be an order of magnitude higher than the reported number, leading to an estimated incidence of approximately $0.17 \%$ per year. Few studies of resistance have been performed in this region (Wattavidanage et al, 1999). The lack of data on malaria-protective genes in South Asia is surprising since some ethnic groups, such as the Tharu in Nepal, have long been known to be resistant to the disease (Terrenato et al, 1988). A large part of Nepal consists of mountains where malaria cannot be transmitted (Gillies, 1988), but the southern part of the country, the Terai area where malaria cases are concentrated is flat and exposed to the malaria parasites $P$. vivax and $P$. falciparum (Sherchand et al, 1995).

The incidence of malaria in the Terai has restricted the settlement of the region, but nevertheless it has been inhabited by aboriginal groups since pre-historical times (van Driem, 2001). The populations designated 'lowland' here fall into this category, as far as is known. Besides these lowland inhabitants, there are other Nepalese populations who live up in the hills but visit low lying areas in the Terai during the daytime when the mosquitoes that spread malaria do not bite - a pattern referred to as "diurnal uphill-downhill" migration (van Driem, 2001). The Terai has also experienced migration from other parts of the country during the Rana period, which started in 1856 and led to deforestation of the region, and from the 1950 s with the implementation of a malaria eradication program (Terrenato et al, 1988). Such populations were not sampled in this study.

It has been proposed that the high frequency of thalassemia among some Nepalese populations such as the Tharu and the Danuwar could explain their biological resistance to malaria (Modiano et al, 1991; Sakai et al, 2000). However, the involvement of other genes in this protection and the resistance in other populations have not been thoroughly investigated (Matsuoka et al, 2003). We have therefore examined the frequency of seven malariaprotective SNPs in 928 healthy individuals from different parts of Nepal in order to investigate whether known African protective alleles also confer resistance in Asia. By comparing populations living successfully in malariaendemic lowland regions, and thus resistant to the disease, with those from malaria-free highland regions, we could investigate the contribution these alleles make to malaria resistance in this region.

\section{SUBJECTS AND METHODS}

\section{Study subjects and PCR amplification}

The sample consisted of 928 healthy individuals representing different groups identified on the basis of ethnicity, language and geography within Nepal (van Driem, 2001; Kraayenbrink et al, 2006). All samples were collected in accordance with the Human Genome Diversity Project Ethics Protocol and with the appropriate approval and cooperation of local institutions. The research aims of the project were explained in Nepali to each individual and informed consent forms in both Nepali and English were signed (van Driem, 2001; Kraayenbrink et al, 2006). Samples were then anonymised before export and DNA analysis. During sampling, care was taken to sample long-term residents. Rural, rather than urban, areas were sampled, both parents belonged to the same ethno-linguistic group as the donor, and the donor's name was characteristic of the ethnic group and the geographic location within Nepal.

Seven SNPs located in the genes $H B B, F Y, G 6 P D$, TNFSF5, TNF, NOS2, and FCGR2A were selected based on previous reports of association with malaria resistance in non-South Asian patients (Kwiatkowski, 2005) and amplified by Polymerase Chain Reaction (PCR). Primers were designed with Primer3 (http://frodo.wi.mit.edu/cgibin/primer3/primer3_www.cgi), screened for primer-dimer and hairpin interactions using AutoDimer (Vallone and Butler, 2004) and combined into two multiplex reactions, M1 (FY, TNFSF5, G6PD and HBB) and M2 (TNF, NOS2 and $F C G R 2 A)$ (Table 1). Amplification was carried out in a 25 $\mu \mathrm{l}$ volume containing $10 \mathrm{ng}$ genomic DNA, $150 \mu \mathrm{M}$ of deoxynucleotide triphosphates (dNTPs; Amersham Biosciences), $1 \mathrm{mM} \mathrm{MgCl}$, $2.0 \mathrm{U}$ of Platinum Taq DNA Polymerase (Invitrogen, Paisley, UK) with 1 x buffer, and the primer final concentrations shown in Table 1. The thermal conditions in an MJ Research DNA Engine Tetrad ${ }^{\mathrm{TM}}(\mathrm{Ge}-$ netic Research Instrumentation, Braintree, UK) were as follows: Denaturation at $94^{\circ} \mathrm{C}$ for $15 \mathrm{~min}$, followed by 15 cycles of touchdown PCR: $94^{\circ} \mathrm{C}$ for $30 \mathrm{sec}, 65^{\circ} \mathrm{C}$ for $30 \mathrm{sec}$, $72^{\circ} \mathrm{C}$ for $45 \mathrm{sec}$, with a $1{ }^{\circ} \mathrm{C}$ decrease in annealing temperature in every cycle, and then 17 cycles of standard PCR $\left(94^{\circ} \mathrm{C}\right.$ for $30 \mathrm{sec}, 50^{\circ} \mathrm{C}$ for $30 \mathrm{sec}, 72^{\circ} \mathrm{C}$ for $45 \mathrm{sec}$ ), followed by extension at $72^{\circ} \mathrm{C}$ for $7 \mathrm{~min}$ and storage at $4^{\circ} \mathrm{C}$. Unincorporated dNTPs and primers were removed by mixing $15 \mu \mathrm{l}$ of these PCR products with a $5 \mu \mathrm{l}$ volume containing 2.0 U of Exonuclease I (USB, Cleveland, USA) and 5.0 U of Shrimp Alkaline Phosphatase (or SAP; USB) for $1 \mathrm{hr}$ at $37^{\circ} \mathrm{C}$ followed by incubation at $80^{\circ} \mathrm{C}$ for $15 \mathrm{~min}$.

Mini-sequencing reaction and capillary electrophoresis Seven mini-sequencing primers were selected from either the reverse or forward direction for each locus and screened for hairpin and primer-dimer interactions as described above. The SNPs at FY, TNFSF5, G6PD and $H B B$ (multiplex 1) and those at TNF, NOS2 and FCGR2A (multiplex 2) were genotyped in two separate mini-sequencing reactions using the ABI Prism ${ }^{\circledR}$ SNaPshot $^{\mathrm{TM}}$ kit (Applied Biosystems, Foster City, USA). The reactions were carried out in a total volume of $5 \mu 1$ containing $2.5 \mu \mathrm{l}$ of SNaPshot Multiplex Ready Reaction mix, $1.0 \mu 1$ of the minisequencing primer mix 1 or 2 (Table 2 ), $1.0 \mu 1$ of deionized water and $0.5 \mu \mathrm{l}$ of the purified PCR products. Thermal cycling conditions consisted of 25 cycles of $96^{\circ} \mathrm{C}$ for $10 \mathrm{sec}, 50^{\circ} \mathrm{C}$ for $5 \mathrm{sec}$, and $60^{\circ} \mathrm{C}$ for $30 \mathrm{sec}$. Unincorporated labeled dideoxynucleotide triphosphates (ddNTPs) were removed by adding $1 \mathrm{U}$ of SAP to the minisequencing products, and incubated at $37^{\circ} \mathrm{C}$ for $1 \mathrm{hr}$, followed by $15 \mathrm{~min}$ 
Table 1: PCR primer sequences for the multiplex amplification of 7 SNPs previously associated with resistance to malaria

\begin{tabular}{|c|c|c|c|c|}
\hline SNP ID & Gene & Base Change $^{\text {a }}$ & PCR primers (final concentration) & $\begin{array}{l}\text { Amplicon } \\
\text { size (bp) }\end{array}$ \\
\hline \multirow[t]{2}{*}{ rs334 } & $H B B$ & $\mathrm{~T} / \mathrm{A}$ & F: $5^{\prime}-$ AGTCAGGGCAGAGCCATCTA-3' $(0.05 \mu \mathrm{M})$ & \multirow[t]{2}{*}{157} \\
\hline & & & 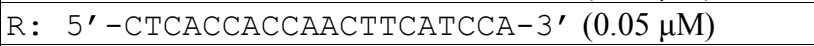 & \\
\hline \multirow[t]{2}{*}{ rs2814778 } & $F Y$ & $\mathrm{C} / \mathrm{T}$ & F : $5^{\prime}$-TCACCCTGTGCAGACAGTTC-3' $(0.1 \mu \mathrm{M})$ & \multirow[t]{2}{*}{226} \\
\hline & & & $\mathrm{R}: 5^{\prime}$-CAAAACAGGAAGACCCAAGG-3' $(0.1 \mu \mathrm{M})$ & \\
\hline \multirow[t]{2}{*}{ rs5030868 } & $G 6 P D^{\mathrm{b}}$ & $\mathrm{T} / \mathrm{C}$ & F : 5' $^{\prime}$ TGCAGCTGTGATCCTCACTC-3' $(0.05 \mu \mathrm{M})$ & \multirow[t]{2}{*}{388} \\
\hline & & & $\mathrm{R}: 5^{\prime}-$ AGGTGGAGGAACTGACCTTG-3' $(0.05 \mu \mathrm{M})$ & \\
\hline \multirow[t]{2}{*}{ rs3092945 } & TNFSF5 & $\mathrm{C} / \mathrm{T}$ & F: $5^{\prime}$-GATTTGCCCAAGGCTCATAG-3' $(0.1 \mu \mathrm{M})$ & \multirow[t]{2}{*}{300} \\
\hline & & & R: 5' $^{\prime}$ AAAAGCATGCTGATGGTTATTAAA-3' $(0.01 \mu \mathrm{M})$ & \\
\hline \multirow[t]{2}{*}{ rs1800629 } & TNF & $\mathrm{G} / \mathrm{A}$ & F $: 5^{\prime}$-CAAACACAGGCCTCAGGACTC-3' $(0.08 \mu \mathrm{M})$ & \multirow[t]{2}{*}{518} \\
\hline & & & R: 5' $^{\prime}$ AGGGAGCGTCTGCTGGCTG-3' $(0.08 \mu \mathrm{M})$ & \\
\hline \multirow[t]{2}{*}{ rs1800482 } & NOS2 & $\mathrm{C} / \mathrm{G}$ & 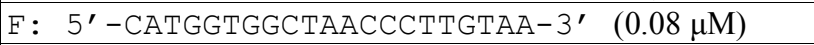 & \multirow[t]{2}{*}{227} \\
\hline & & & $\mathrm{R}: 5^{\prime}$-CTGCTCATTGCAACTTCTGC-3' $(0.08 \mu \mathrm{M})$ & \\
\hline \multirow[t]{2}{*}{ rs1801274 } & FCGRIIA & $\mathrm{C} / \mathrm{T}$ & F $: 5^{\prime}-\mathrm{CCAGAATGGAAAATCCCAGA}-3^{\prime}(0.08 \mu \mathrm{M})$ & \multirow[t]{2}{*}{163} \\
\hline & & & R: $5^{\prime}$-CAGACTCCCCATACCTTGGA-3' $(0.08 \mu \mathrm{M})$ & \\
\hline
\end{tabular}

Notes:

${ }^{\mathrm{a}}$ the protective allelic state is listed first.

${ }^{\mathbf{b}}$ both forward and reverse PCR primers had been previously published (Tishkoff et al, 2001)

The SNPs in bold were polymorphic in the studied population.

Table 2: Minisequencing primers for the multiplex detection of 7 SNPs previously associated with resistance to malaria

\begin{tabular}{|c|c|c|}
\hline Gene & Sequencing primers (final concentration in the primer mix) & Length (nt) \\
\hline$H B B$ & $5^{\prime}$-ATGGTGCACCTGACTCCTG-3' $(0.1 \mu \mathrm{M})$ & 19 \\
\hline$F Y$ & 5'-GACTGACTCTCATTAGTCCTTGGCTCTTA-3' $(0.6 \mu \mathrm{M})$ & 29 \\
\hline G6PD & $5^{\prime}$-GACTGACTGACTGACATCTGGTCCTCACGGAACAGGGAG-3' $(0.05 \mu \mathrm{M})$ & 39 \\
\hline$\overline{T N F S F 5}$ & $\begin{array}{l}5^{\prime}-\text { GACTGACTGAGACTGACTATTTTCCCTATTCTGAACTGTTACATCAGCA-3' } \\
(0.7 \mu \mathrm{M})\end{array}$ & 49 \\
\hline$T N F$ & $\begin{array}{l}5^{\prime}-\text { GACTGACTGACTGACTGACTGAGACTGAAGGCAATAGGTTTTGAGGGGCATG-3' } \\
(0.6 \mu \mathrm{M})\end{array}$ & 52 \\
\hline NOS2 & $5^{\prime}$-GACTGACTGAGACTGACAGATCACTTGAGCTTCAGAGTTCGA-3' $(0.4 \mu \mathrm{M})$ & 42 \\
\hline$F C G K$ & $5^{\prime}-$ TGGAGAAGGTGGGATCCAAA-3 & 20 \\
\hline
\end{tabular}

Note: The mini-sequencing primers for the underlined genes were chosen based on the reverse strand and the scored alleles should be the reverse of those shown in Table 1.

at $80^{\circ} \mathrm{C}$. One tenth of the purified minisequencing reaction $(0.5 \mu \mathrm{l})$ was mixed with $9.0 \mu \mathrm{l} \mathrm{Hi-Di}$ formamide and $0.5 \mu \mathrm{l}$ GeneScan-120 LIZ size standard (Applied Biosystems, Warrington, UK). This mixture was then denatured for 2 min at $96^{\circ} \mathrm{C}$ and analysed in the ABI PRISM 3100 Genetic Analyzer, using filter set E5 and a $36 \mathrm{~cm}$ capillary array filled with POP4 polymer (Applied Biosystems). Allele scoring was performed using GeneMapper 3.0 software (Applied Biosystems).

\section{Data analyses}

Allele and genotype frequencies were obtained by direct counting and differences in allele frequencies were assessed by means of Fisher's exact test in the 928 healthy individuals residing in either lowlands $(\mathrm{n}=146)$ or highlands $(\mathrm{n}=782)$ of Nepal. The hypothesis of HardyWeinberg equilibrium (HWE) was tested using the approach of Guo and Thompson implemented in Arlequin
2.0 (Schneider et al, 2000). Conventional pairwise $\mathrm{F}_{\text {st }}$ distances and analysis of molecular variance (AMOVA) were obtained with Arlequin for the 18 populations whose sample size was greater than 20. For AMOVA, populations were pooled according to whether they reside in lowlands or highlands, and the results were then compared with no grouping. Differences in allele frequencies for the 18 populations were assessed by the Mann-Whitney test using SPSS v 14.0.

\section{RESULTS AND DISCUSSION}

We typed seven SNPs in genes previously associated with protection to malaria in Africa (Kwiatkowski, 2005), namely $H B B, F Y, G 6 P D, T N F S F 5, T N F, N O S 2$, and $F C G R 2 A$, in 928 healthy individuals from Nepal, a country in Asia where the disease is also endemic. Out of the seven SNPs, five were found to be fixed for the non- 
protective allele at $H B B, F Y, G 6 P D, T N F S F 5$ and NOS2 (Table 1). Surprisingly, the protective allele at rs5030868 in G6PD which has been observed in other South Asian countries, such as India (Balgir, 2006) was absent from the large Nepalese sample examined here. The non-protective allele at these SNPs is also fixed in all HapMap samples, with the exception of Africans (http://www.hapmap.org/index.html.en), and also in non-Africans from dbSNP (http://www.ncbi.nlm.nih.gov/ entrez/query.fcgi? $\mathrm{db}=\mathrm{Snp})$. On the other hand, the SNPs in $T N F$ (rs1800629) and FCGR2A (rs1801274) were polymorphic in the Nepalese population, and the protective alleles were found at an overall frequency of $93 \%$ and $27 \%$, respectively. In the combined Nepalese sample, the genotype frequencies at these SNPs were found to depart significantly from HWE $(p<0.0001)$.

We then investigated the correlation of these two SNPs with the regions in Nepal that are exposed to malaria or not, i.e. lowlands and highlands. The frequency of the protective allele at $T N F$ in our entire data set $(n=928)$ was $89 \%$ in the lowlands and $94 \%$ in the highlands, and the difference in this allele frequency was statistically significant (Fisher's exact test, $p=0.02$ ). In combined populations from the highlands a significant departure from HWE was observed $(p=0.0002)$, whereas in the lowlands the hypothesis of random association of alleles was not rejected $(p=0.0679)$. For FCGRIIA, no significant difference was seen in the frequency of the protective allele between lowland (22\%) and highland (28\%) populations; the genotype frequencies in the combined populations from the highlands departed from HWE $(p=0.001)$ but those in the lowlands did not $(p=0.326)$.
Subsequently we looked at the correlation of these SNPs with malaria exposure in the 18 individual populations of Nepal which had a sample size greater than $20 \quad(n=586$, Figure 1). No significant departures from HW expectations were found in individual populations (Table 2), which suggested that the $p$ values obtained above reflected population subdivision present in the country.

Then, it was surprising to see among the individual populations that for $T N F$ (rs1800629), four out of five populations living in malarial areas actually had lower frequencies of the protective allele than populations living in malaria-free regions (Figure 1A). Two groups showed frequencies greater than $25 \%$ of the non-protective allele at rs1800629, the Sherpa and the Danuwar (Figure 1A, Table 3). Both of them live in the malaria-free highlands of Nepal, which could explain the unconstrained higher frequency of the non-protective allele. However, it is striking that some of the other highland populations are fixed or almost fixed for the protective allele (Figure 1A, Table 3). For FCGRIIA (rs1801274), a similar lack of association of the protective allele with malarial regions of Nepal was observed (Fig. 1B). A frequency greater than $52 \%$ of the protective allele was seen in two populations living at high altitude, High Caste Newar and Chantyal, whereas this allele was found to be as rare as $18 \%$ in Kumal and Majhi Bote, two groups exposed to the disease (Figure 1B, Table 3). However, the differences in allele frequencies between the highland and lowland populations were not statistically significant at either TNF or FCGRIIA (Mann-Whitney U test). This lack of correlation between the protective alleles at both TNF and FCGRIIA and the distribution of malaria suggests that malaria did not select for these alleles in Nepal.

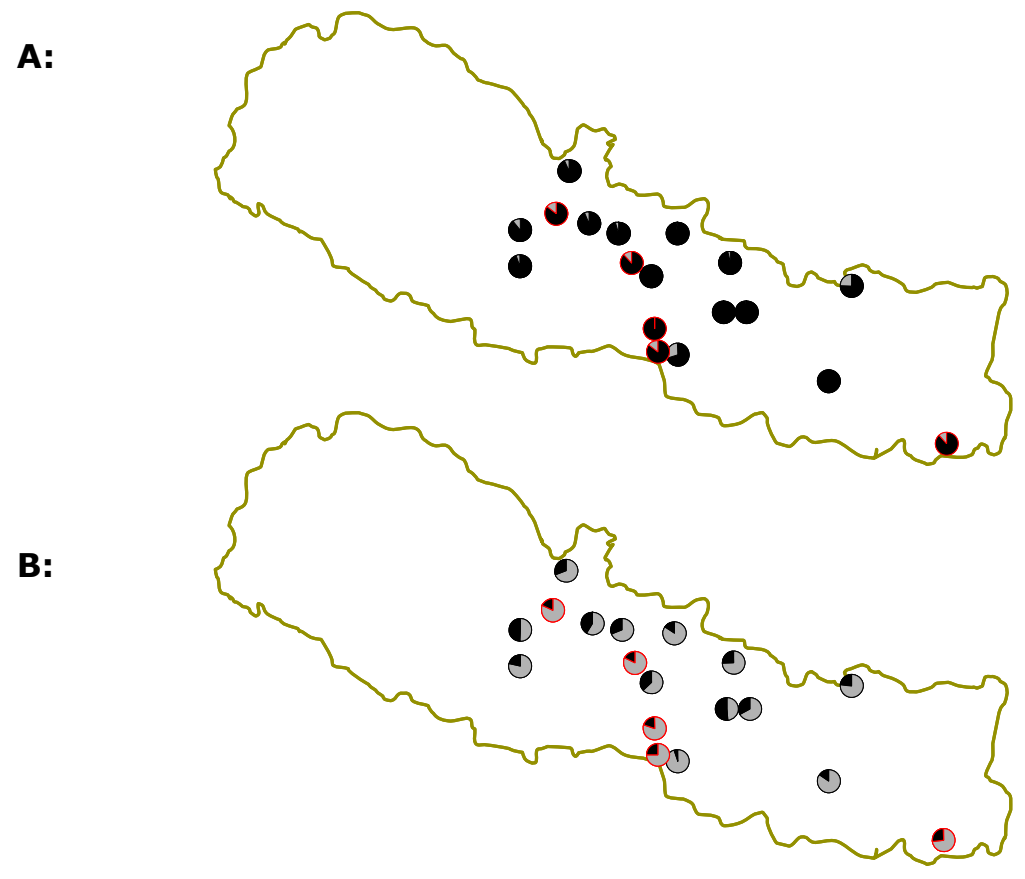

Figure 1: Distribution of malaria-protective alleles (black sectors) in Nepal. Red lines indicate populations from malaria-endemic lowland regions, black lines from malaria-free highland regions. A) rs1800629 (TNF), B) rs1801274 (FCGRIIA). 
Table 3: Genotype and allele ${ }^{a}$ frequencies in 18 populations from lowlands and highlands of Nepal

\begin{tabular}{|c|c|c|c|c|c|c|c|c|c|c|c|}
\hline \multirow[t]{3}{*}{ Population } & \multirow[t]{3}{*}{ n } & \multicolumn{10}{|c|}{ Genotype } \\
\hline & & \multicolumn{5}{|c|}{$T N F$ (rs1800629) } & \multicolumn{5}{|c|}{ FCGRIIA (rs1801274) } \\
\hline & & G & GG & GA & $\mathrm{AA}$ & $p^{b}$ & $\mathrm{C}$ & $\mathrm{CC}$ & $\mathrm{CT}$ & TT & $p^{b}$ \\
\hline Baram & 38 & 1.00 & 1.00 & & & N.A ${ }^{c}$ & 0.37 & 0.14 & 0.46 & 0.40 & 0.07 \\
\hline Chantyal & 23 & 0.89 & 0.79 & 0.21 & & 1.00 & 0.50 & 0.25 & 0.5 & 0.25 & 0.08 \\
\hline Chepang $^{\mathrm{d}}$ & 27 & 1.00 & 1.00 & & & N.A & 0.20 & 0.04 & 0.32 & 0.62 & 1.00 \\
\hline Danuwar & 30 & 0.70 & 0.49 & 0.42 & 0.09 & 0.69 & 0.05 & & 0.10 & 0.90 & 1.00 \\
\hline Dhimal & 22 & 0.89 & 0.79 & 0.21 & & 1.00 & 0.27 & 0.08 & 0.20 & 0.72 & 0.63 \\
\hline Dura & 35 & 0.96 & 0.92 & 0.08 & & 1.00 & 0.31 & 0.10 & 0.43 & 0.47 & 1.00 \\
\hline Ghale & 25 & 0.98 & 0.96 & 0.04 & & 1.00 & 0.16 & & 0.13 & 0.70 & 1.00 \\
\hline Gurung & 46 & 0.93 & 0.86 & 0.14 & & 1.00 & 0.41 & 0.17 & 0.48 & 0.35 & 0.23 \\
\hline High Caste Newar & 29 & 1.00 & 1.00 & & & N.A & 0.52 & 0.27 & 0.50 & 0.23 & 1.00 \\
\hline Kumal & 25 & 0.88 & 0.77 & 0.21 & 0.02 & 0.29 & 0.18 & 0.03 & 0.30 & 0.67 & 1.00 \\
\hline Magar & 45 & 0.94 & 0.88 & 0.11 & 0.01 & 0.11 & 0.21 & 0.05 & 0.33 & 0.62 & 0.38 \\
\hline Majhi Bote & 27 & 0.85 & 0.72 & 0.26 & 0.02 & 0.45 & 0.19 & 0.04 & 0.31 & 0.65 & 0.19 \\
\hline Newar & 50 & 0.99 & 0.98 & 0.02 & & 1.00 & 0.33 & 0.11 & 0.44 & 0.45 & 0.75 \\
\hline Sherpa & 24 & 0.75 & 0.56 & 0.38 & 0.06 & 0.59 & 0.23 & 0.05 & 0.35 & 0.60 & 0.56 \\
\hline Tamang & 48 & 0.97 & 0.94 & 0.06 & & 1.00 & 0.26 & 0.07 & 0.38 & 0.55 & 1.00 \\
\hline Thakali & 29 & 0.93 & 0.86 & 0.13 & 0.01 & 0.10 & 0.31 & 0.09 & 0.43 & 0.48 & 1.00 \\
\hline Tharu & 34 & 0.85 & 0.72 & 0.25 & 0.03 & 0.12 & 0.25 & 0.06 & 0.38 & 0.56 & 0.39 \\
\hline Wambule & 29 & 1.00 & 1.00 & & & N.A & 0.16 & 0.03 & 0.26 & 0.71 & 0.11 \\
\hline
\end{tabular}

Notes:

${ }^{\mathrm{a}}$ Frequency of the protective alleles $\mathrm{G}$ and $\mathrm{C}$ at $T N F$ and FCGRIIA, respectively

${ }^{\mathrm{b}} p$ values after testing for departure from Hardy-Weinberg equilibrium (random association of alleles in diploid individuals)

${ }^{\mathrm{c}}$ N.A. not applicable

${ }^{\mathrm{d}}$ The populations in bold live in the malarial lowlands of Nepal. The remaining groups live in regions of high altitudes, which are malaria-free

Finally, we assessed whether or not the inter-population diversity between groups living in malaria-free regions and those exposed to the disease varied significantly. By means of AMOVA, we found that $91 \%$ and $95 \%$ of the entire variation at rs1800629 (TNF) and rs1801274 (FCGRIIA), respectively, was observed within populations. In contrast, the amount of variation between groups was zero for $T N F$ and $0.54 \%(p=0.22$; not significantly different from zero) for FCGRIIA, whereas the $\mathrm{F}_{\text {st }}$ (distance between populations among groups) was $9 \%$ for TNF and $5 \%$ for FCGRIIA. The observed low $\mathrm{F}_{\text {st }}$ values and the AMOVA analyses further support our conclusion that it is unlikely that selection by malaria has significantly influenced the frequencies of the protective alleles at $T N F$ and FCGRIIA in Nepal.

Although genes such as G6PD, TNF and FCGRIIA have previously been associated with malaria resistance in parts of Asia (Balgir, 2006; Matsuoka et al, 2003; Omi et al, 2002; Wattavidanage et al, 1999), the disease did not play an important role in selecting or maintaining the protective alleles of these genes in the populations that we have ex- amined in Nepal. Recent migration and admixture could equalise gene frequencies between populations, but both our sampling strategy and the high differentiation between populations observed at other loci (results not shown) lead us to conclude that such factors cannot explain our results. It is possible that selection for other functions of these genes has dominated in Nepal, but perhaps more likely either that the populations and disease have not co-existed in this region for long enough for malaria to influence allele frequencies detectably, or that genetic drift dominates to such an extent in these small populations (Parkin et al, in press) that it overwhelms any selective force by malaria. The investigation of additional SNPs and genes that may contribute to malaria resistance, especially those involved in the human immune response, could help to distinguish between the above hypotheses.

\section{ACKNOWLEDGEMENTS}

We thank all DNA donors, the organisations and volunteers in Nepal, who gave us their assistance; Mark A Jobling and Emma Parkin for comments on the manuscript, 
Cara Woodwark for bioinformatics support, and three referees for suggesting improvements to the manuscript. The research was conducted in association with the Centre for Nepal and Asian Studies (CNAS) at Kirtipur under the Bilateral Agreement for Academic Cooperation between Tribhuvan University and Leiden University, as part of the European Science Foundation EUROCORES Programme OMLL. CPC and DRC-S were supported by the Arts and Humanities Research Board and the EC Sixth Framework Programme under Contract no. ERAS-CT-2003-980409. TK, GvD, PdK were supported by the NWO (Netherlands Organisation for Scientific Research) grant 231-70-001, and CT-S was supported by The Wellcome Trust, UK.

\section{STATEMENT OF COMPETING INTERESTS}

The authors declared no competing interests.

\section{LIST OF ABBREVIATIONS}

HWE: Hardy-Weinberg equilibrium SAP: Shrimp Alkaline Phosphatase SNP: Single Nucleotide Polymorphism

\section{ELECTRONIC-DATABASE INFORMATION}

http://frodo.wi.mit.edu/cgi-bin/primer3/primer3_www.cgi http://w3.whosea.org/en/Section10/Section21/Section340.htm http://www.hapmap.org/index.html.en http://www.ncbi.nlm.nih.gov/entrez/query.fcgi?db=Snp

\section{REFERENCES}

Balgir RS. 2006. Do tribal communities show an inverse relationship between sickle cell disorders and glucose-6-phosphate dehydrogenase deficiency in malaria endemic areas of CentralEastern India? Homo, 57, 163-176.

Boldt AB, Luty A, Grobusch MP et al. 2006. Association of a new mannose-binding lectin variant with severe malaria in $\mathrm{Ga}-$ bonese children. Genes Immun, 7, 393-400.

Gillies MT. 1988. Anopheline mosquitos: vector behaviour and bionomics. In: Wernsdorfer WH MI (ed) Malaria: principles and practice of malariology. Churchill Livingstone, Edinburgh, pp 453-485.

Kondrashin AV. 1992. Malaria in the WHO Southeast Asia region. Indian J Malariol, 29, 129-160.

Kraayenbrink T, de Knijff P, van Driem GL et al. 2006. Language and Genes of the Greater Himalayan Region. OMLL Vol http://www.le.ac.uk/genetics/maj4/Himalayan_OMLLreport.pdf

Kwiatkowski DP. 2005. How malaria has affected the human genome and what human genetics can teach us about malaria. Am J Hum Genet, 77, 171-192.

Matsuoka H, Jichun W, Hirai M et al. 2003. Two cases of glucose-6-phosphate dehydrogenase-deficient Nepalese belonging to the G6PD Mediterranean-type, not India-Pakistan sub-type but Mediterranean-Middle East sub-type. J Hum Genet, 48, 275-277.

Miller LH, Mason SJ, Clyde DF and McGinniss MH. 1976. The resistance factor to Plasmodium vivax in blacks. The Duffyblood-group genotype, FyFy. N Engl J Med, 295, 302-304.

Modiano G, Morpurgo G, Terrenato L et al. 1991. Protection against malaria morbidity: near-fixation of the alphathalassemia gene in a Nepalese population. Am J Hum Genet, 48, 390-397.

Omi K, Ohashi J, Patarapotikul J et al. 2002. Fcgamma receptor IIA and IIIB polymorphisms are associated with susceptibility to cerebral malaria. Parasitol Int, 51, 361-366.
Parkin EJ, Kraayenbrink T, Opgenort JR et al. Diversity of 26locus Y-STR haplotypes in a Nepalese population sample: Isolation and drift in the Himalayas. Forensic Sci Int, in press. doi: 10.1016/j.forsciint.2006.05.007

Rich SM, Licht MC, Hudson RR and Ayala FJ. 1998. Malaria's Eve: evidence of a recent population bottleneck throughout the world populations of Plasmodium falciparum. Proc Natl Acad Sci U S A, 95, 4425-4430.

Sakai Y, Kobayashi S, Shibata H et al. 2000. Molecular analysis of alpha-thalassemia in Nepal: correlation with malaria endemicity. J Hum Genet, 45, 127-132.

Schneider S, Roessli D and Excoffier L. 2000. Arelquin: a software for population genetics data analysis. 2.000 edn. Genetics and Biometry Lab, Dept. of Anthropology, University of Geneva

Sherchand JB, Shrestha MP, Shreshta BL, Banerjee MK and Shakya S. 1995. A preliminary study on field trials with insecticide-treated mosquito nets for malaria control in a rural endemic community of Nepal. Journal of the Nepal Medical Association, 33, 195-203.

Terrenato L, Shrestha S, Dixit KA et al. 1988. Decreased malaria morbidity in the Tharu people compared to sympatric populations in Nepal. Ann Trop Med Parasitol, 82, 1-11.

Tishkoff SA, Varkonyi R, Cahinhinan N et al. 2001. Haplotype diversity and linkage disequilibrium at human G6PD: recent origin of alleles that confer malarial resistance. Science, 293, 455-462.

Tournamille C, Colin Y, Cartron JP and Le Van Kim C. 1995. Disruption of a GATA motif in the Duffy gene promoter abolishes erythroid gene expression in Duffy-negative individuals. Nat Genet, 10, 224-228.

Vallone PM and Butler JM. 2004. AutoDimer: a screening tool for primer-dimer and hairpin structures. Biotechniques, 37, 226-231.

van Driem GV. 2001. Languages of the Himalayas: An Ethnolinguistic Handbook of the Greater Himalayan Region, containing an Introduction to the Symbiotic Theory of Language (2 volumes). Brill, Leiden.

Wattavidanage J, Carter R, Perera KL et al. 1999. TNFalpha*2 marks high risk of severe disease during Plasmodium falciparum malaria and other infections in Sri Lankans. Clin Exp Immunol, 115, 350-355.

\section{SHORT COPYRIGHT STATEMENT}

This is an open access article, published under the terms of the Licence for Users available at http://www.libpubmedia.co.uk/ MedJ/LicenceForUsers.pdf. This licence permits noncommercial use, distribution and reproduction of the article, provided the original work is appropriately acknowledged with correct citation details. 